\title{
NOISE CHARACTERISTICS DURING WELDING IN ARGON-CONTAINING SHIELDING GASES
}

\author{
O.G. LEVCHENKO ${ }^{1}$, V.A. KULESHOV ${ }^{1}$ and A.Yu. ARLAMOV ${ }^{2}$ \\ ${ }^{1}$ E.O. Paton Electric Welding Institute, NASU \\ 11 Bozhenko Str., 03680, Kiev, Ukraine. E-mail: office@paton.kiev.ua \\ ${ }^{2}$ NTUU «Kyiv Polytechnic Institute» \\ 6/2 Dashavskaya Str., 03056, Kiev, Ukraine
}

\begin{abstract}
The aim of this work was to measure the characteristics of acoustic noise at the workplace during manual TIG welding in argon and semiautomatic welding in $\mathrm{Ar}+\mathrm{CO}_{2}$. Welding was carried out inside the welding metal cabin of $1.8 \mathrm{~m}$ height, $2.0 \mathrm{~m}$ width and $2.4 \mathrm{~m}$ depth. The noise parameters were measured using the integrated sound level meter of the first class of accuracy. The point of measurement at the welder's workplace was located at the distance of $0.55 \mathrm{~m}$ from welding arc. A single measurement was conducted for about $60 \mathrm{~s}$ at the running ventilation unit. It was established that in TIG welding the value of equivalent sound level at the welder's workplace in the wide range of rated values of current $I=45-210$ A does not exceed $64 \mathrm{dBA}$, that is significantly lower than the sanitary-hygienic standard of $80 \mathrm{dBA}$ and is comparable with the level of $57 \mathrm{dBA}$ of the background noise. In semiautomatic welding in $\mathrm{Ar}+\mathrm{CO}_{2}$ the noise level at the welder's workplace in the range of rated values of current $I=80-250$ A exceeds MAL and reaches $96 \mathrm{dBA}$. The limit of safe working area as to noise was established at the distance of $2 \mathrm{~m}$ from the place of welding. The data of this work can be used for sanitary-hygienic assessment of noise episodes of specific welding processes in shielding gases. 6 Ref., 3 Tables, 5 Figures.
\end{abstract}

Keywords: welding in shielding gas, argon, mixture of $\mathrm{Ar}+\mathrm{CO}_{2}$, acoustic noise, characteristics

In this paper, which is a continuation of work [1], the results of investigations of noise characteristics at the welder's workplace are given during welding in shielding gases, namely in manual TIG welding and semiautomatic welding.

Manual TIG welding. Welding was performed in the KEMPPI OY argon-arc DC welding machine Master 2200 (Finland) inside the welding metal cabin of $1.8 \mathrm{~m}$ height, $2 \mathrm{~m}$ width and $2.4 \mathrm{~m}$ depth. The steel (St3) plates of $12 \mathrm{~mm}$ thickness being welded were placed on the table and welded in argon using tungsten electrode of $2.4 \mathrm{~mm}$ diameter.

The noise parameters were measured using the «Bruel \& Kjaer» integrated sound level meter (model 2230) of the first class of accuracy, whose functional and technical characteristics meet the requirements of interstate standard GOST 17187-2010 [2]. The measuring point was situated at the arm's length distance $(0.55 \mathrm{~m})$ from the welding arc.

The noise measuring at a typical workplace was conducted in accordance with the requirements of DSN 3.3.6.037-99 [3]. In all the measurements the noise levels with frequency correction $A$ (general noise level) were recorded, which are required for sanitary-hygienic assessment: equivalent noise level $L_{\text {eq }}$, maximum $L_{\text {op max }}$ and minimum $L_{\mathrm{op} \text { min }}$ sound pressure levels.
A single measurement was carried out for about $60 \mathrm{~s}$ at the operating ventilation unit. The characteristics of background noise $L_{\text {back }}$ produced by the auxiliary equipment (current generator, ventilation unit) and other sources of noise located in welding shop, are the following, dBA: $L_{\mathrm{eq}}=56.5$; $L_{\text {op } \max }=72.7 ; L_{\text {op min }}=53.3$.

The data on the noise values generated during welding at the welder's workplace in the range of rated welding current values of 45-210 A, are given in Table 1.

Let us define the noise value $L_{\mathrm{w}}$ generated directly by welding process. The value of the measured noise $L_{\text {meas }}$ consists of two parts: background noise $L_{\text {back }}$ and welding noise $L_{\mathrm{w}}$. Using the principle of additivity of noise energy flows (intensities) at the point of measurement, it can be shown [4] that $L_{\mathrm{w}}$ value is determined by expression

$$
L_{\mathrm{W}}=L_{\text {back }}+10 \lg \left(10^{\left(L_{\text {meas }}-L_{\text {back }}\right) / 10}-1\right) .
$$

Hence, it follows that if the value of measured noise is significantly higher than the value of background noise, as far as the difference $L_{\text {meas }}-$ $L_{\text {back }} \geq 10$, then it can be assumed with a high degree of accuracy (within the measurement error

Table 1. Noise level $L_{\text {meas }}$ measured at the welder's workplace

\begin{tabular}{|c|c|c|c||}
\hline$I_{\mathrm{w}}, \mathrm{A}$ & $L_{\mathrm{eq}}, \mathrm{dBA}$ & $L_{\mathrm{op} \max }, \mathrm{dBA}$ & $L_{\mathrm{op} \min }, \mathrm{dBA}$ \\
\hline 45 & 59.6 & 71.6 & 54.9 \\
\hline 100 & 60.2 & 65.4 & 57.2 \\
\hline 150 & 63.1 & 68.2 & 57.5 \\
\hline 210 & 65.9 & 80.0 & 57.2 \\
\hline
\end{tabular}


$L_{\mathrm{c}(\mathrm{l}}, \mathrm{dBA}$

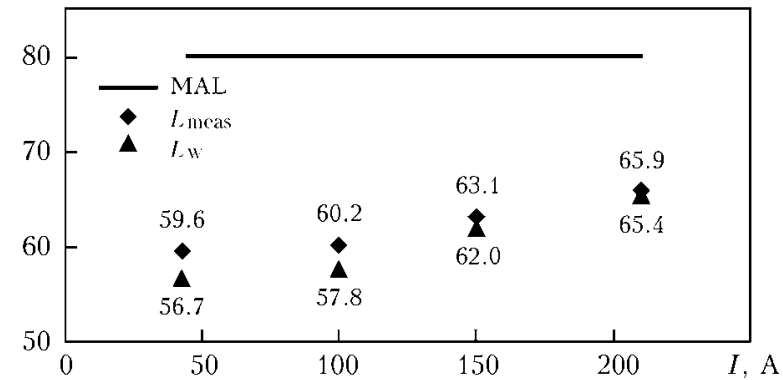

Figure 1. Dependence of noise levels $L_{\text {meas }}$ and $L_{\mathrm{w}}$ on welding current at the welder's workplace

of $\pm 1 \mathrm{~dB}$ ) that $L_{\text {meas }} \approx L_{\mathrm{w}}$. As far as in this case this condition is not fulfilled, let us calculate the $L_{\mathrm{w}}$ value according to formula (1), using the data from Table 1 . The noise level $L_{\mathrm{w}}$ at the welder's workplace at $I_{\mathrm{w}}=45$ A corresponds to 56.7, at $100 \mathrm{~A}-57.8$, at $150 \mathrm{~A}-62.0$ and at $210 \mathrm{~A}-65.4 \mathrm{dBA}$.

Graphically, the values of $L_{\mathrm{eq}}$ are given in Figure 1.

It can be seen that the noise, produced by welding process, is much lower than the maximum admissible level (MAL) equal to $80 \mathrm{dBA}$ [3]. The noise naturally decreases at decrease in current as the release of energy in the air drops also.

A negligible change in the noise level was observed in a rather wide range of changes in rated values of current: the growth in current by 4.7 times caused the noise amplification only by $12 \%$. The contribution of background noise to the general noise generation increases at decrease in welding current and is comparable to the value of welding noise. Thus, TIG welding does not require the carrying out of protective anti-noise measurements.

Semiautomatic welding in $\mathrm{Ar}+\mathrm{CO}_{2}$. Semiautomatic welding of steel (St3) plates of $4 \mathrm{~mm}$ thickness was carried out in the mixture of $\mathrm{Ar}+$ $+18 \% \mathrm{CO}_{2}$ using copper-plated wire Sv-08G2S of $1.2 \mathrm{~mm}$ diameter. In welding the «Lincoln Electric» inverter Invertec V350-PRO (USA) was used. The equipment for wire feed was «Lincoln Electric» LP-72.

The conditions of welding and measurement procedure were similar to those used in the previous case. The data measurements of the values

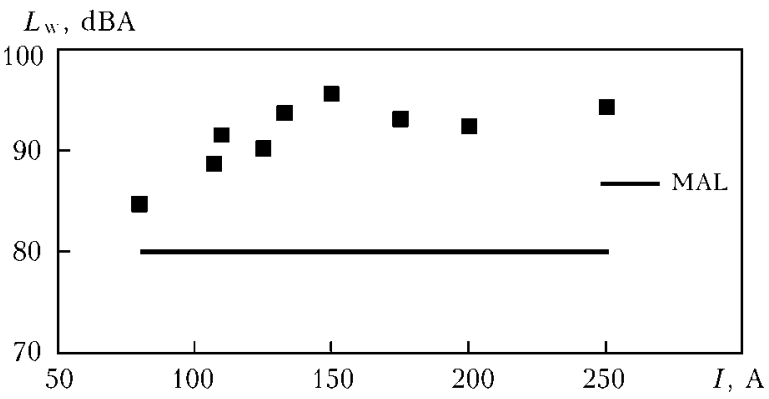

Figure 2. Level of welding noise at the workplace during semiautomatic welding in $\mathrm{Ar}+\mathrm{CO}_{2}$ mixture
Table 2. Measured noise level $L_{\text {meas }}$ and calculated values of welding noise $L_{\mathrm{w}}$ at the welder's workplace

\begin{tabular}{||c|c|c|c|c|}
\hline \multirow{2}{*}{$I_{\mathrm{w}}, \mathrm{A}$} & \multicolumn{3}{|c|}{$L_{\text {meas }}, \mathrm{dBA}$} & $L_{\mathrm{w}}, \mathrm{dBA}$ \\
\cline { 2 - 5 } & $L_{\mathrm{eq}}$ & $\left(L_{\mathrm{op}}\right)_{\max }$ & $\left(L_{\mathrm{op}}\right)_{\min }$ & $L_{\mathrm{eq}}$ \\
\hline 80 & 84.9 & 91.9 & 75.6 & 84.7 \\
\hline 107 & 88.7 & 93.6 & 81.6 & 88.6 \\
\hline 110 & 91.5 & 96.0 & 84.2 & 91.5 \\
\hline 125 & 90.2 & 95.6 & 85.6 & 90.1 \\
\hline 133 & 93.6 & 96.5 & 88.6 & 93.6 \\
\hline 150 & 95.5 & 98.6 & 81.8 & 95.5 \\
\hline 175 & 93.1 & 97.4 & 78.0 & 93.1 \\
\hline 200 & 92.4 & 97.1 & 76.2 & 92.4 \\
\hline 250 & 94.2 & 98.0 & 75.6 & 94.2 \\
\hline \multicolumn{5}{|l}{} \\
\hline
\end{tabular}

$L_{\text {meas }}$ and $L_{\mathrm{w}}$ are given in Table 2. The level of background noise $L_{\text {back }}$ at the welder's workplace is the following, dBA: $L_{\mathrm{eq}}=71.1 ; L_{\mathrm{op} \max }=$ $=84.7 ; L_{\text {op } \min }=64.1$.

Graphically, the data of measurement values are given in Figure 2.

The measurement results show a significant excess in the MAL value, especially at the intensive welding modes. At the same time, two areas of dependence of the noise level on welding current are observed, qualitatively different from each other. At low currents in the range of 80150 A the noise is amplified, but at further growth of welding current the noise level falls. This is explained by decrease in the level of acoustic emission due to reduction of arc length observed at high values of current during «submerged arc» welding mode [5].

Let us note the linear character of the dependence in the area of noise level growth, which is indicated by a sufficiently high square value of linear correlation $R^{2}=0.9$ (Figure 3 ). In the specified range a negligible noise amplification of approximately by $11 \%$ is recorded at twice increase in current.

To determine the safe working area as to its noise level for the auxiliary personnel, the measurements of noise level at different distances from the source of noise were carried out. The data of noise level measurements at the distance from welding arc of 1, 1.5 and $2 \mathrm{~m}$ are given in Table 3 .

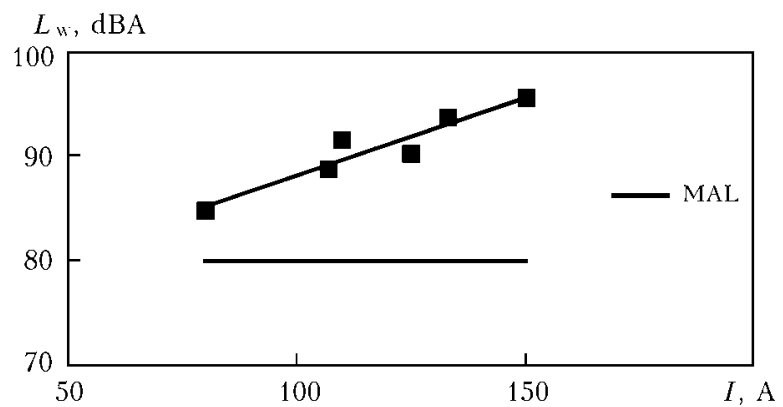

Figure 3. Level of welding noise at the workplace during semiautomatic welding in $\mathrm{Ar}+\mathrm{CO}_{2}$ in the linear region of noise growth 
Table 3. Noise level $L_{\text {meas }}$ at various distance from the welding arc

\begin{tabular}{||c|c|c|c||}
\hline \multirow{2}{*}{$I_{\mathrm{w}}, \mathrm{A}$} & $L_{\mathrm{eq}}$ & $L_{\text {op max }}$ & $L_{\text {op min }}$ \\
\cline { 2 - 4 } & \multicolumn{3}{|c|}{$1 \mathrm{~m}$} \\
\hline 80 & 83.3 & 92.9 & 74.6 \\
\hline 107 & 84.8 & 92.0 & 81.7 \\
\hline 125 & 85.7 & 92.0 & 84.7 \\
\hline 133 & 86.1 & 92.7 & 85.2 \\
\hline \multicolumn{5}{|c|}{$1.5 \mathrm{~m}$} \\
\hline 80 & 81.3 & 90.8 & 72.0 \\
\hline 107 & 81.9 & 91.4 & 71.7 \\
\hline 125 & 82.3 & 91.7 & 72.4 \\
\hline 133 & 82.2 & 91.6 & 72.9 \\
\hline \multicolumn{5}{|c|}{} & \multicolumn{3}{|c|}{} \\
\hline 80 & 78.1 & 87.5 & 70.8 \\
\hline 107 & 78.6 & 87.9 & 70.5 \\
\hline 125 & 79.1 & 88.1 & 71.4 \\
\hline 133 & 79.0 & 88.0 & 71.8 \\
\hline
\end{tabular}

Using the means of data analysis MS Excel, it can be shown that the obtained data are well approximated by linear dependencies, which is confirmed by rather high square values of linear correlation $R^{2}$ lying in the range of $0.92-0.97$. Let us note that linear dependence between the noise level and the value of welding current is also characteristic for manual arc welding using coated electrodes [1]. Graphically, the measurements data and their linear trends are illustrated in Figure 4. At removal from the welding place the noise level is reduced and already at the distance of $2 \mathrm{~m}$ its value is getting lower than MAL. Thus, the limit of the safe working area as to noise is in the range of distances from welding arc of $1.5-2.0 \mathrm{~m}$.

At large distances from the source of noise the measured values of noise level slightly depend on welding mode and, in fact, due to scattering of sound waves the noise level is reduced down to background level (Figure 5).

As the level of noise, generated at the workplace, is much higher than MAL, it is necessary to use protective anti-noise measurements to reduce the impact of noise on welder [6], for example, to provide him with appropriate means of individual protection, or to reduce his working hours, according to [3]. We should also note that the personnel staying close to the place of such welding works (but not closer than $2 \mathrm{~m}$ ) does not require protection.

\section{Conclusions}

1. In manual TIG welding the noise level at the welder's workplace in the wide range of rated values of welding current (45-210 A) does not exceed $64 \mathrm{dBA}$, which is much lower than the

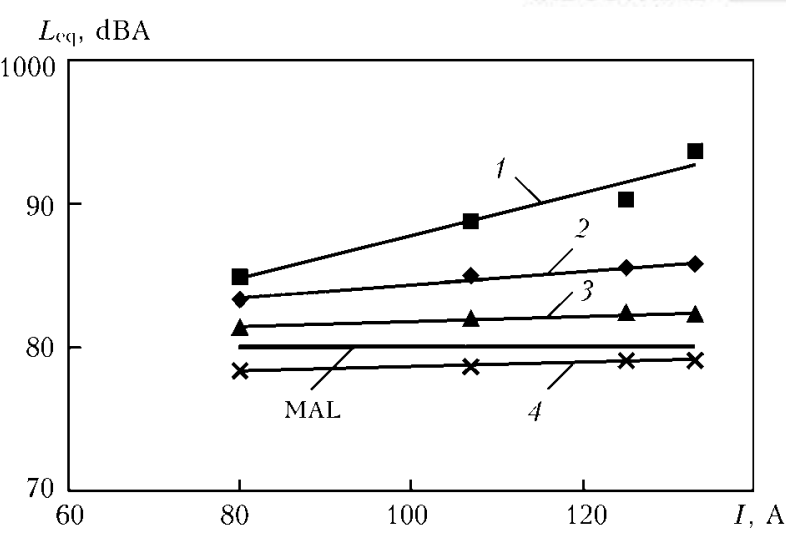

Figure 4. Levels of measured noise during semiautomatic welding in shielding gas at distance of 0.55 (1), 1.0 (2), 1.5 (3) and 2.0 (4) $\mathrm{m}$ from the welding place

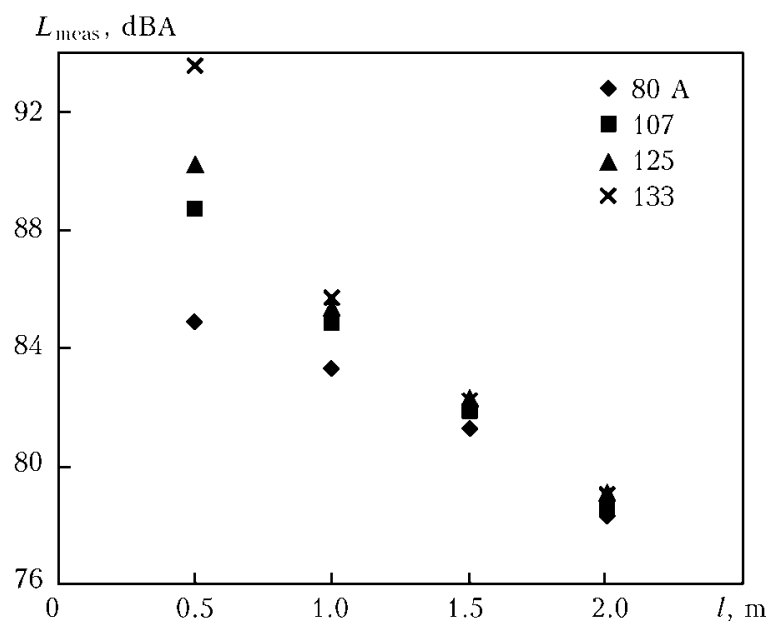

Figure 5. Dependence of noise $L_{\text {meas }}$ on distance from the welding arc at different values of current

established sanitary-hygienic standard $(\mathrm{MAL}=$ $=80 \mathrm{dBA}$ ) and is comparable to the background noise level of $57 \mathrm{dBA}$.

2. In semiautomatic welding in $\mathrm{Ar}+\mathrm{CO}_{2}$ the noise level at the welder's workplace in the range of rated values of current (80-250 A) exceeds MAL and reaches $96 \mathrm{dBA}$. With increase in welding current from 80 to 150 A the noise is amplified, and the further increase in current leads to damping of noise due to immersion of arc into the weld pool. The working area safe as to noise is at distance of $1.5-2.0 \mathrm{~m}$ from the welding arc.

1. Levchenko, O.G., Kuleshov, V.A., Arlamov, A.Yu. (2014) Sanitary-hygienic evaluation of noise in manual arc welding with covered electrodes. The Paton Welding J., 9, 45-48.

2. GOST 17187-2010: Noise dosimeters. Pt 1: Technical requirements. Introd. 01.07.2012.

3. $D S N$ 3.3.6.037-99: Sanitary norms of industrial noise, ultrasound and infrasound. Introd. 01.12.1999.

4. Grinchenko, V.T., Vovk, Sh.V., Matsipura, V.T. (2007) Principles of acoustics. Kyiv: Naukova Dumka.

5. Volchenko, V.N. Yampolsky, V.M., Vinokurov, V.A. et al.' (1988)' Theory of welding processes. Moscow: Vysshaya Shkola.

6. Levchenko, O.G., Kuleshov, V.A. (2013) Industrial noises. Pt 3. Svarshchik, 4, 34-39.

Received 13.05.2015 